\title{
Testing a Genetic Structure of Blood-Injury-Injection Fears
}

\author{
A.C. Page ${ }^{1 *}$ and N.G. Martin ${ }^{2}$ \\ ${ }^{1}$ Department of Psychology, University of Western Australia \\ ${ }^{2}$ Queensland Institute of Medical Research, Brisbane, Australia
}

Multivariate genetic analyses were used to examine the genetic and environmental contributions to individual differences in fears of blood, injury, and injections in 659 twin pairs who completed questions concerning fear and fainting around blood, injury, and injections, and fainting in situations not involving blood, as well as the personality scales of Neuroticism, and Harm Avoidance. There was significant familial aggregation of blood fears but univariate analyses were unable to distinguish between additive genetic or shared environmental variables, or both, as the cause. The same was true of blood fainting. Non-bloodinjury fainting was best explained by a model assuming shared and unique environmental variables. However, multivariate genetic analyses, which capitalise on extra information contained by all the covariance terms, indicated that the variance in bloodinjury-injection fear was principally attributable to unique environmental events specific to this fear and additive genetic factors shared with fainting. The data are discussed in the context of models of blood-injury phobia that identify the need to consider separate etiological mechanisms for fear and fainting. Am. J. Med. Genet. (Neuropsychiatr. Genet.) 81:377-384, 1998.

(c) 1998 Wiley-Liss, Inc.

KEY WORDS: multivariate genetic analyses; twin pairs; fears

Contract grant sponsor: National Health and Medical Research Council of Australia; Contract grant numbers: 941177, 971232; Contract grant sponsor: National Institute of Alcoholism and Alcohol Abuse.

*Correspondence to: A.C. Page, Department of Psychology, University of Western Australia, Nedlands WA 6907, Australia. E-mail: andrew@psy.uwa.edu.au

Received 23 September 1997; Revised 10 March 1998

\section{INTRODUCTION}

It is clear that specific phobias involve multiple causes. Rachman [1991] has organised the existing data by suggesting that there are three pathways to a specific phobia: classical conditioning (i.e., pairing of a potentially phobic stimulus with an aversive outcome), information, and vicarious acquisition (i.e., acquiring fear after observing a model reacting fearfully in the presence of a potentially phobic stimulus). Considering Rachman's account from the perspective of behaviour genetics, the identified causes are most readily conceptualised as instances of environmental rather than genetic factors. Consistent with these conclusions, Kendler et al. [1992] found that the major contributor to specific phobias were unique environmental factors [rather than additive genetic or environmental factors common to family members; see also Skre et al., 1993].

Given this background, what reasons would there be for expecting to find a genetic contribution to a specific phobia, and in particular blood-injury phobia [Marks, 1988; Page, 1994]? The first reason for expecting a genetic contribution to certain specific phobias relates to the role that individual differences in relevant personality variables which may predispose one individual to react more strongly to an environmental event than another [Andrews et al., 1994; Carey, 1990]. For example, Eysenck's conception of Neuroticism [Eysenck and Eysenck, 1975] is that there are individual differences in the tendency to arouse rapidly under stress. Consequently, it would be reasonable to expect that such people would be more likely to acquire specific phobias because they would react with greater fear during a conditioning experience, worry about threatrelated information, or become more afraid when observing another display stimulus-elicited fear. For instance, Skre et al., [1993] found a heritable component to Posttraumatic Stress Disorder; an anxiety disorder which, by definition, is triggered by an environmental event. In a similar way to Neuroticism, Cloninger's [Cloninger et al., 1991] construct of Harm Avoidance may make a person vulnerable to acquire specific phobias. People who tend to avoid harm would react by avoiding stimuli that associated with threat and danger. Nonetheless, given the proportionally small role

(c) 1998 Wiley-Liss, Inc. 
that genetic factors played in Kendler's analysis, the proportion of variance accounted for by these measures was expected to be small.

A second reason for expecting a genetic contribution to specific phobias arises from speculations about the causes of symptoms that are unique to blood-injury phobia. Blood-injury phobia is unique among the phobias. In contrast to other phobias, approximately three quarters of sufferers report fainting in the presence of their phobic object [Öst et al., 1984; Page, 1996; Thyer et al., 1985]. This fainting is part of a diphasic response pattern that characterizes blood-injury phobia. During the first phase, the sufferer exhibits the classic fight or flight response [Cannon, 1927], mediated by the sympathetic nervous system (SNS). During the second phase, the sufferer switches into a "conservationwithdrawal" response [Henry, 1976]. Some argue that the parasympathetic nervous system [PNS; Vingerhoets, 1984] mediates the latter phase, while others argue that there is a rapid alternation between sympathetic and parasympathetic arousal [Engel, 1978]. Although the precise physiology of the latter phase remains unclear, Page [1994] has argued that the occurrence of two responses, suggests an etiological mechanism additional to those that give rise to phobic fear generally.

If there is a separate etiology generating fainting around blood, then why do fear and fainting co-occur? One possible answer can be found in Kleinknecht and Lenz's [1989] data. They found that the onset of fainting around blood and injury precedes the onset of fear and that the number of past faints and the expectations of the future probability of fainting predicted present avoidance. Given that fainting is generally an aversive experience, it would be understandable that a person who tended to faint at the sight of blood and injury would come to fear and avoid such stimuli. If the argument that fainting around blood and injury causes subsequent fear of these stimuli is accepted the question becomes "what caused the fainting?"

A speculative and preliminary answer to this question is that the origins of fainting around blood lie in genetic rather than environmental factors. Some support for this position comes from family studies, where Kleinknecht and Lenz [1989] found that the parentchild correspondence was greater for blood-injury fainting than fear. Similarly, Öst [1992] reported that people who were more likely to faint (i.e., blood phobics) were in turn more likely to report a first degree relative with phobic avoidances of blood than people who were less likely to faint (i.e., injection phobics). While data from family studies confound genetic and shared environmental variables, they are consistent with a supposition that a tendency to faint around blood is an inherited individual difference, and because such fainting is aversive, people who experience such fainting will become avoidant of stimuli that predict future fainting.

Given that there are two classes of reasons for expecting blood-injury fears to demonstrate an heritable component, it is reasonable to examine the data pertaining to this issue. The family studies converge on the conclusion that blood-injury phobias run in families (with the number of patients reporting a positive family history ranging from 27-68\%; [Marks, 1988; Ost et al., 1984]. Studies also typically report that these rates contrast with the lower rates of reported of positive family among people with specific phobias more generally [11-31\%; Fyer et al., 1990; Marks, 1987, 1988]. Together these data imply that one cause of bloodinjury phobia lies within the family (either inherited or acquired). They further imply that either the familybased cause is stronger for blood-injury phobia than other phobias or that blood-injury phobia involves the summation of factors that causes phobias more generally with a factor unique to blood-injury phobia (e.g., a tendency to faint around blood).

The data from twin studies complement these data with evidence that concordance rates for monozygotic (MZ) twins are greater than dizygotic twins (DZ). Averaging the heritability indices for the blood-injurydeath factor of the Fear Survey Schedule [see Page, 1994] generates an estimated heritability of .46 (range .30-.72). While the mean heritability for blood-injury fear was numerically higher than the estimates for the other fears (separation $\mathrm{h}^{2}=.26$; social fears $\mathrm{h}^{2}=39$; and fears of physical dangers $\mathrm{h}^{2}=.42$ ), the differences between phobias were much smaller than the family data would predict.

More recently, Neale and colleagues have extended these data by examining the genetics of blood-injury fears and phobias in a population sample of twins [Neale et al., 1994]. They interviewed 541 monozygotic (MZ) and 388 dizygotic (DZ) female American twins using a structured diagnostic interview [the Diagnostic Interview Schedule Version III-A; Robins and Helzer, 1985]. They conducted a series of univariate analyses on the self-reported fears of blood, needles, hospitals, and illness. They concluded that a model postulating the chief sources of variance to be shared family or "common" environment (C) and individual-specific or unique environment (E), explained these fears adequately. Even so, a model postulating additive genetic effects (A) and unique environment (E) could explain the observed correlations between $\mathrm{MZ}$ and $\mathrm{DZ}$ twins equally well. The research made a valuable contribution to the literature. Earlier studies only provided heritability estimates, yet Neale and colleagues partitioned the variance among three sources (i.e., A, C, and E). However, they acknowledge that low power tempers confidence in the accuracy of their estimates of the variance attributable to genetic and environmental factors.

In order to replicate and extend the work of Neale and colleagues, we sought to examine whether we could reproduce the estimates of genetic and environmental contributions reported by Neale and colleagues in a sample of Australian twins. If the Australian and American twin samples converged upon similar models and parameter estimates, it is less likely that low power may have compromised the conclusions of Neale and colleagues.

However, we sought also to extend the finding in two ways. First, we sought to test the role of personality variables (namely, Neuroticism and Harm Avoidance) which are known to make a person vulnerable to de- 
velop an anxiety disorder [see Andrews et al., 1990a,b; Andrews et al., 1994; Barlow, 1988]. Second, we sought to examine the extent to which the tendency to faint contributed to fears of these stimuli. In each of these endeavours, we were also interested to partitioning variance into the three sources used in Neale et al. [1994].

We sought to examine systematically the relative genetic and environmental contributions of three sets of variables to blood-injury fears. The first set of variables can be summarised under the label "trait anxiety" and was measured by Eysenck's Neuroticism and Cloninger's Harm Avoidance. The second set of variables included those related to fainting, where fainting could have occurred in the presence of blood, injury, and injections or in some other situation. The final variables were those genetic and environmental causes that were related to blood-injury fears and independent of trait anxiety and fainting-related variables.

\section{METHOD Subjects}

Participants were 1,866 twin individuals enrolled on the National Health and Mental Research Council's Australian Twin Register. The twins were part of an unselected cohort born before 1965, who had completed a health and lifestyle questionnaire in 1980-1982, a follow-up questionnaire in 1988, and a telephone interview in 1993. In 1993-1995, a subset of this sample (who lived in Melbourne and Canberra,) were asked to supply a blood sample for biochemical and DNA analyses. Blood samples were obtained in two ways; either twins could come to the urban laboratories to be bled by one of our staff, or they could visit their own doctors for phlebotomy and have the blood sample sent by courier. Those who presented to the laboratories in the three cities were asked three questions about blood-injection fears and fainting after blood had been taken. A degree of attrition occurred, first because paired data were only available on 762 twin pairs and second, of these twin pairs, complete data on every measure of interest were available on only 659 pairs. Of these subjects, there were $242 \mathrm{MZ}$ female and $94 \mathrm{MZ}$ male twin pairs, 125 female DZ and 59 male DZ twin pairs, and 139 opposite sex DZ twin pairs. The mean age of subjects was $45.2(\mathrm{SD}=11.2)$. Zygosity had been previously assigned from responses to questionnaires about similarity of appearance and confusion by people who knew them. Further questioning and inspection of photographs resolved inconsistencies. Subsequently, typing of independent, highly polymorphic males in a subsample of 200 same sex pairs found no inconsistencies with zygosity as previously assigned above [Duffy, unpublished observations].

\section{Procedure}

The subjects were asked three questions pertaining to blood-injury-injection fears and were asked to respond "yes" or "no": 1) "Are you overly fearful around blood, injury, or injections?" 2) "Have you ever fainted in a situation that involved blood, injury, or injections?" and 3) "Have you ever fainted in circumstances that did not involve blood, injury, or injections?" Subjects who answered "yes" to any of these questions were then asked to write down the age at which they first were overly fearful, or fainted in blood or non-blood situations. (The items about the age of first occurrence were answered by so few subjects that the responses were not analyzed.) The participants had completed other relevant questionnaires at earlier surveys. Specifically, they had completed the full Eysenck Personality Questionnaire [Eysenck and Eysenck, 1975] in 1980 and a short form (54 items) of Cloninger's Tridimensional Personality Questionnaire in 1988 [Cloninger et al., 1991; Jardine et al., 1984]. For present purposes, the 23-item Neuroticism subscale of the full EPQ and the short (18 items) Harm Avoidance scale of the TPQ were used.

\section{Statistical Methods}

Data were prepared using Prelis 2.12a [Jöreskog and Sörbom 1993a]. The resulting polychoric correlations and asymptotic covariances matrices were analyzed using the methods of genetic analysis described by Neale and Cardon [1992]. LISREL 8.12a [Jöreskog and Sörbom, 1993b] provided weighted least squares estimates of model parameters and goodness of fit statistics. A detailed, concise rationale and account of assumptions can be found in Heath, Cloninger, and Martin [1994]. Briefly, the genetic models tested postulated three sources of variance in the observed scores: additive genetic variance (A), common or shared family environment (C), and unique or individual-specific environment (E). Therefore, the total variance in an observed trait is the sum of additive genetic variance, shared environmental variance, and unique environment (i.e., $\mathrm{a}^{2}+\mathrm{c}^{2}+\mathrm{e}^{2}$ ). Models assuming three sources (ACE), two sources ( $\mathrm{AE}$ and $\mathrm{CE})$, or one source (E) of variance were tested, using the $\chi^{2}$ statistic to see how well they were able to fit the data.

The multivariate analyses used Cholesky decomposition [see Heath et al., 1994; Neale and Cardon, 1992; for detailed discussions] to partition variances. Cholesky factorization is a method of triangular decomposition where the first variable (Neuroticism) is assumed to be caused by a latent variable that can explain variance in all remaining observed variables (Harm Avoidance, Non-Blood Faintness, Faintness, and Blood Fears). The second variable (Harm Avoidance) is assumed to be caused by a second latent variable that can explain variance in the second and subsequent observed variables (Non-Blood Faintness, Faintness, and Blood Fears). Therefore, the second latent variable is constrained from predicting variance of the first observed variable. This pattern continues until the final observed variable (in the present case, blood fears) is caused by a latent variable that is constrained from explaining variance in any other component of the model. Initially, a Cholesky decomposition is specified for each source of variance $\mathrm{A}, \mathrm{C}$, or $\mathrm{E}$ and as in the univariate case, $\mathrm{ACE}, \mathrm{AE}, \mathrm{CE}$, and $\mathrm{E}$ models were fitted to the data and $\chi^{2}$ values and Akaike's Information Criterion (AIC; Akaike, 1987] were used to identify the model with the best fit. 


\section{RESULTS Validity of Sampling}

The validity of the sampling involved in the present study was tested by comparing the twin pairs of whom both members contributed data with the twin pairs of whom only one member participated (i.e., singletons). These analyses were conducted for males and females separately.

In general, there were no significant differences between complete and incomplete twin pairs on any of the measures (see Table I). The chief exception was evident among males, where the rate of reported blood, injury, and injection fear was significantly lower $\left(\chi^{2}(1)=\right.$ 4.32; $P=.039)$. These results suggest that male twins who were overly fearful of blood, injury, or injections were less likely than average to participate in the study. Presumably these avoidances occurred because males, who are generally less likely to participate in research anyway, were more likely to refuse the offer to attend a testing session that involved providing a blood sample if they had fears of such situations. Furthermore, when comparing MZ with DZ twins, it was clear that male MZ twins were more likely to report a later onset of fear and lower Harm Avoidance scores. Importantly, there was no evidence of such avoidances among females. This selective attrition among male subjects introduced potential bias into the data that was further compounded by the small cell sizes among male subjects. Therefore, subsequent analyses were restricted to female subjects. Polychoric correlations were calculated (because these optimise the bivariate normality, whatever the raw scale) and the relevant correlations and standard errors for same sex female pairs are displayed in Table II. As an aside, it is noteworthy that our data imply that research projects requesting subjects to provide a blood sample may introduce selection biases among male participants such that those who may fear and avoid medical settings associated with blood and injections will be less likely to participate.

\section{Univariate Analyses}

From Table III it is evident that for EPQ Neuroticism, the best fitting model is the one assuming additive genetic and unique environmental effects. Similarly, for the harm avoidance subscale of the TPQ, the
AE model has a good fit, but the CE model has an equally good fit. However, the model omitting both $\mathrm{C}$ and $\mathrm{A}$ fails badly, implying that there is significant familial aggregation, but that with our data set one cannot rule out either $\mathrm{A}$ or $\mathrm{C}$ as the cause. The patterns for non-blood-injury and blood-injury fainting are different. Non-blood-injury fainting is best explained by a model assuming shared and unique environmental variables, this model being superior to the one assuming additive genetic and unique environmental variables. Blood fainting, like blood fears, was best explained by a model assuming unique environmental plus additive genetic and/or shared environmental variables.

\section{Multivariate Analyses}

The Cholesky decomposition for females found that both the $\mathrm{CE}\left[\chi^{2}(65)=189.36 ; \mathrm{AIC}=59.36\right]$ and $\mathrm{AE}$ $\left[\chi^{2}(65)=184.48 ; \mathrm{AIC}=54.48\right]$ models were significantly better able to explain the data than the model postulating unique environment alone $\left[\chi^{2}(80)=472.48\right.$; $\mathrm{AIC}=312.48$ see Table IV]. However, the ACE model was the best fitting model $\left[\chi^{2}(50)=152.71 ; \mathrm{AIC}=2.71\right]$. This model was then simplified by deleting nonsignificant parameters and the final model $\left[\chi^{2}(79)=180.01 ; \mathrm{AIC}=22.01\right]$ is displayed in Figure 1.

\section{DISCUSSION}

The univariate analyses suggested that blood fear was associated principally with factors shared by family members. Although the present investigation was unable to identify whether these shared factors were genetic or environmental, unique environmental experiences explained only a third of the variance in blood fears. In passing, it is noteworthy that the MZ correlations were high relative to the DZ correlations, indicating the possibility of dominant genetic effects. In contrast to blood fears, only a third of the variance in fainting around blood was attributable to factors shared by family members (although once again, the present investigation was unable to identify whether these shared factors were genetic and/or environmental). While studies with greater power will be required to discriminate between the $\mathrm{AE}$ and $\mathrm{CE}$ models (or more probably, deciding in favour of the ACE model) in the future, the present data imply that the role of unique environmental experiences may not be equivalent for

TABLE I. Comparison Between Singletons, Twin Pairs, and MZ and DZ Twins on Measures of Trait Anxiety, and Blood-Injury Fear and Fainting*

\begin{tabular}{|c|c|c|c|c|c|c|c|c|}
\hline & \multicolumn{2}{|c|}{ Females } & \multicolumn{2}{|c|}{ Males } & \multicolumn{2}{|c|}{ Females } & \multicolumn{2}{|c|}{ Males } \\
\hline & $\begin{array}{c}\text { Single } \\
(\mathrm{n}=235)\end{array}$ & $\begin{array}{c}\text { Pair } \\
(\mathrm{n}=1003)\end{array}$ & $\begin{array}{c}\text { Single } \\
(\mathrm{n}=138)\end{array}$ & $\begin{array}{c}\text { Pair } \\
(\mathrm{n}=517)\end{array}$ & $\begin{array}{c}\mathrm{MZ} \\
(\mathrm{n}=544)\end{array}$ & $\begin{array}{c}\mathrm{DZ} \\
(\mathrm{n}=461)\end{array}$ & $\begin{array}{c}\text { MZ } \\
(\mathrm{n}=222)\end{array}$ & $\begin{array}{c}\mathrm{DZ} \\
(\mathrm{n}=295)\end{array}$ \\
\hline Blood fear & $6.4 \%$ & $7.3 \%$ & $7.2 \% \mathrm{a}$ & $3.3 \%^{\mathrm{a}}$ & $7.4 \%$ & $7.2 \%$ & $4.5 \%$ & $2.4 \%$ \\
\hline Age first blood fear & 15.5 & 12.2 & 11.4 & 19.2 & 12.3 & 12.2 & $26.0^{\mathrm{a}}$ & $8.9^{\mathrm{a}}$ \\
\hline Blood faint & $9.7 \%$ & $10.2 \%$ & $12.2 \%$ & $10.6 \%$ & $9.0 \%$ & $11.5 \%$ & $11.3 \%$ & $10.2 \%$ \\
\hline Age first blood faint & 19.4 & 21.2 & 19.3 & 21.4 & 22.2 & 20.3 & 21.2 & 21.6 \\
\hline Non-blood faint & $34.0 \%$ & $30.0 \%$ & $16.5 \%$ & $16.1 \%$ & $28.5 \%$ & $31.5 \%$ & $14.0 \%$ & $17.6 \%$ \\
\hline Age first non-blood faint & 21.2 & 19.4 & 20.6 & 22.7 & 19.9 & 20.0 & 24.2 & 21.8 \\
\hline EPQ Neuroticism & 11.1 & 11.3 & 8.7 & 9.3 & 11.4 & 11.2 & 8.9 & 9.6 \\
\hline TPQ Harm Avoidance & 7.8 & 8.0 & 6.0 & 6.2 & 8.0 & 7.9 & $5.5^{\mathrm{a}}$ & $6.7^{\mathrm{a}}$ \\
\hline
\end{tabular}

*n, number of individuals.

${ }^{a}$ Numbers indicated with same letter are significantly different $(P<.05)$. 


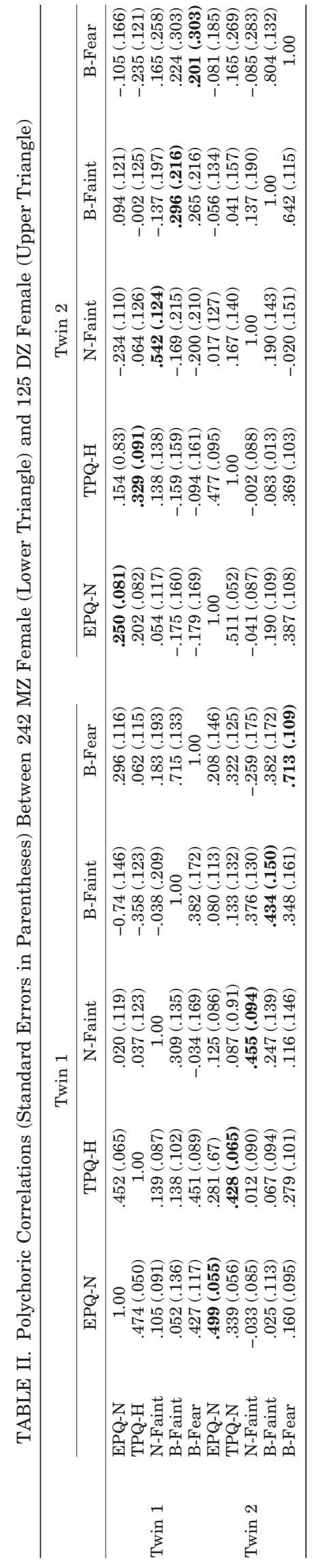

the symptoms of fear and fainting experienced around blood, injury and injections. That is, the origins of fainting around blood may lie in the context of unique environmental experiences, whereas the origins of fear may lie in factors (either genetic or environmental) that are shared between family members.

While previous research has not examined the heritability of faintness, the results with blood, injury injection fears are somewhat similar to those reported by Neale et al. [1994; Table IV]. The best fitting models of blood $(\mathrm{A}=56 \% ; \mathrm{E}=44 \%)$ and injection $(\mathrm{A}=46 \%$; $\mathrm{E}$ $=54 \%$ ) fears indicated that additive genetic factors were accounting for about half of the variance, which was similar to, but lower than, the $71 \%$ in the present study. One possible explanation for this difference could lie in the different questions that the subjects were asked. Neale et al. asked subjects about the lifetime occurrence of fears, whereas the present study inquired about present fears. Given that specific phobias generally have their onset in childhood and adolescence and the point prevalence reduces with age, and assuming that the heritable component to fears acts to amplify the reaction to environmental causes of phobias [Andrews et al., 1994], then fears that are still present in an adult sample are more likely to demonstrate higher heritability than fears that occurred over the lifetime. If true, this effect is going to be exaggerated by relative age of the two samples, where Neale's subjects had a mean age of 30.1 , which is on average 15 years younger than the present sample.

However, before discussing the possible implications for theory, it is important to consider how the multivariate analysis refined this picture. Consistent with previous research, Neuroticism has a substantial genetic component (41\%), which is partly shared with Harm Avoidance (17\%). There is a large unique environmental component to Neuroticism (59\%), some of which is shared with Harm Avoidance (7\%), fainting around blood (2\%), and fears around blood (7\%). Similar to Neuroticism, Harm Avoidance involves a further additive genetic component (28\%) and a large unique environmental component (48\%), both of which are shared with blood fears ( $1 \%$ and $6 \%$, respectively). Fainting in situations not involving blood, injury, or injections is associated with both shared (53\%) and nonshared (46\%) environmental components. The more specific fainting in situations not involving blood is largely determined by additive genetic variance shared with non-blood fainting (64\%), with the remainder of the variance be attributed to unique environmental effects.

Considering fears in the presence of blood, injury, and injections, these parameter estimates suggest that most of the variance in blood-injury fears can be partitioned into variance attributable to unique environmental effects (32\%) and to additive genetic effects associated with fainting (55\%; but not the fainting around blood and injury). This is not to say that the factors that give rise to fainting around blood are irrelevant in terms of blood-injury fears but rather that once the variance explicable in terms of fainting more generally is taken into account there is no more variance to account for. Reiterating points made above, the 
TABLE III. Weighted Least Squares Estimates of Genetic and Environmental Variance Components for Blood-Injury-Injection Fears and Associated Variables in MZ and DZ Female Twins

\begin{tabular}{|c|c|c|c|c|c|c|}
\hline & $\begin{array}{l}\text { Additive } \\
\text { genetic }\end{array}$ & $\begin{array}{c}\text { Shared } \\
\text { environment }\end{array}$ & $\begin{array}{l}\text { Nonshared } \\
\text { environment }\end{array}$ & $\mathrm{df}$ & $\chi^{2}$ & $\mathrm{AIC}$ \\
\hline \multicolumn{7}{|c|}{ Neuroticism } \\
\hline $\mathrm{ACE}$ & .50 & $.00^{\mathrm{a}}$ & .50 & 0 & 0.00 & 0.00 \\
\hline $\mathrm{AE}$ & .50 & - & .50 & 1 & 0.00 & -2.00 \\
\hline $\mathrm{CE}$ & - & .42 & .58 & 1 & 6.44 & 4.44 \\
\hline $\mathrm{E}$ & - & - & 1.00 & 2 & 90.74 & 86.74 \\
\hline \multicolumn{7}{|c|}{ Harm avoidance } \\
\hline $\mathrm{ACE}$ & .19 & .23 & .58 & 0 & 0.00 & 0.00 \\
\hline $\mathrm{AE}$ & .45 & - & .55 & 1 & 1.42 & -0.58 \\
\hline $\mathrm{CE}$ & - & .40 & .61 & 1 & 0.79 & -1.21 \\
\hline $\mathrm{E}$ & - & - & 1.00 & 2 & 56.86 & 52.86 \\
\hline \multicolumn{7}{|c|}{ Non-blood faint } \\
\hline $\mathrm{ACE}$ & $.00^{*}$ & .49 & .51 & 0 & 0.00 & 0.00 \\
\hline $\mathrm{AE}$ & .53 & - & .46 & 1 & 5.60 & 3.60 \\
\hline $\mathrm{CE}$ & - & .49 & .51 & 1 & 0.31 & -1.69 \\
\hline $\mathrm{E}$ & - & - & 1.00 & 2 & 42.22 & 38.22 \\
\hline \multicolumn{7}{|c|}{ Blood faint } \\
\hline $\mathrm{ACE}$ & .44 & $.00^{\mathrm{a}}$ & .56 & 0 & 0.00 & 0.00 \\
\hline $\mathrm{AE}$ & .45 & - & .55 & 1 & 0.12 & -1.88 \\
\hline $\mathrm{CE}$ & - & .38 & .61 & 1 & 0.27 & -1.73 \\
\hline $\mathrm{E}$ & - & - & 1.00 & 2 & 10.26 & 6.26 \\
\hline \multicolumn{7}{|c|}{ Blood fear } \\
\hline $\mathrm{ACE}$ & .71 & $.00^{\mathrm{a}}$ & .29 & 0 & 0.26 & 0.26 \\
\hline $\mathrm{AE}$ & .71 & - & .29 & 1 & 0.26 & -1.74 \\
\hline $\mathrm{CE}$ & - & .66 & .35 & 1 & 2.52 & 0.52 \\
\hline $\mathrm{E}$ & - & - & 1.00 & 2 & 43.27 & 39.27 \\
\hline
\end{tabular}

${ }^{a}$ On a lower bound.

remaining variance is chiefly distributed between unique environmental effects associated with Neuroticism $(7 \%)$ and unique environmental effects associated with Harm Avoidance (6\%). It is also important to recall that the additive genetic factor that gives rise to blood, injury, injection fear is the same genetic factor that gives rise to fainting in such circumstances $(64 \%$ of the variance).

Thus, consistent with the univariate analysis, around a third of the variance in blood fears was attributable to unique environmental experiences specific to blood fears. However, the remaining variance was partitioned between an additive genetic factor that caused both fainting and fear around blood and equally between unique environments that also gave rise to the two trait anxiety measures, Neuroticism and Harm Avoidance. This last point is consistent with Carey [1990], who has speculated that both genes and environment contribute to a general tendency towards fearfulness, which in turn predisposes some people to ac- quire fearful behaviour when placed in certain environments.

Together these results permit greater refinement of existing conceptualizations of blood, injury, injection fears. First, it appears that the co-occurrence between blood fainting and fear arises from an additive genetic factor that is shared between fainting and blood fears. A second noteworthy aspect of these data is the independent contributions of unique environments that are associated with Neuroticism and also with Harm Avoidance. Why should these there be two processes rather than a single "trait anxiety"? One possible explanation lies in the data of Page, et al. [1997], who found that symptoms of blood and injection "fears" could not be accounted for in terms of a single factor model. Rather the best fitting model divided symptoms into "faintness," "anxiety," and "tension." The authors suggested that the tension factor could reflect the anticipatory anxiety experienced before exposure to a phobic stimulus and the anxiety factor could represent

TABLE IV. Genetic and Environmental Path Coefficients Under a Cholesky Decomposition Method (Females Only) for the Best Fitting ACE Model

\begin{tabular}{|c|c|c|c|c|c|c|c|c|c|c|c|c|c|c|c|}
\hline & \multicolumn{5}{|c|}{ Additive genetic } & \multicolumn{5}{|c|}{ Shared environment } & \multicolumn{5}{|c|}{ Nonshared environment } \\
\hline & I & II & III & IV & $\mathrm{V}$ & I & II & III & IV & $\mathrm{V}$ & I & II & III & IV & $\mathrm{V}$ \\
\hline $\mathrm{N}$ & .46 & & & & & .41 & & & & & .79 & & & & \\
\hline HA & .22 & .43 & & & & .37 & .27 & & & & .08 & .69 & & & \\
\hline $\mathrm{Nfa}$ & .09 & .08 & .31 & & & -.09 & .14 & .65 & & & .02 & .01 & .66 & & \\
\hline Bfa & $.00^{\mathrm{a}}$ & .37 & .59 & $.00^{\mathrm{a}}$ & & -.07 & -.14 & -.27 & $.00^{\mathrm{a}}$ & & .14 & -.18 & .11 & -.59 & \\
\hline $\mathrm{Bfe}$ & -.02 & .40 & .55 & $.00^{\mathrm{a}}$ & $.00^{\mathrm{a}}$ & -.06 & -.11 & -.25 & $.00^{\mathrm{a}}$ & $.00^{\mathrm{a}}$ & .29 & .11 & -.03 & -.09 & .60 \\
\hline
\end{tabular}

an a lower bound. 


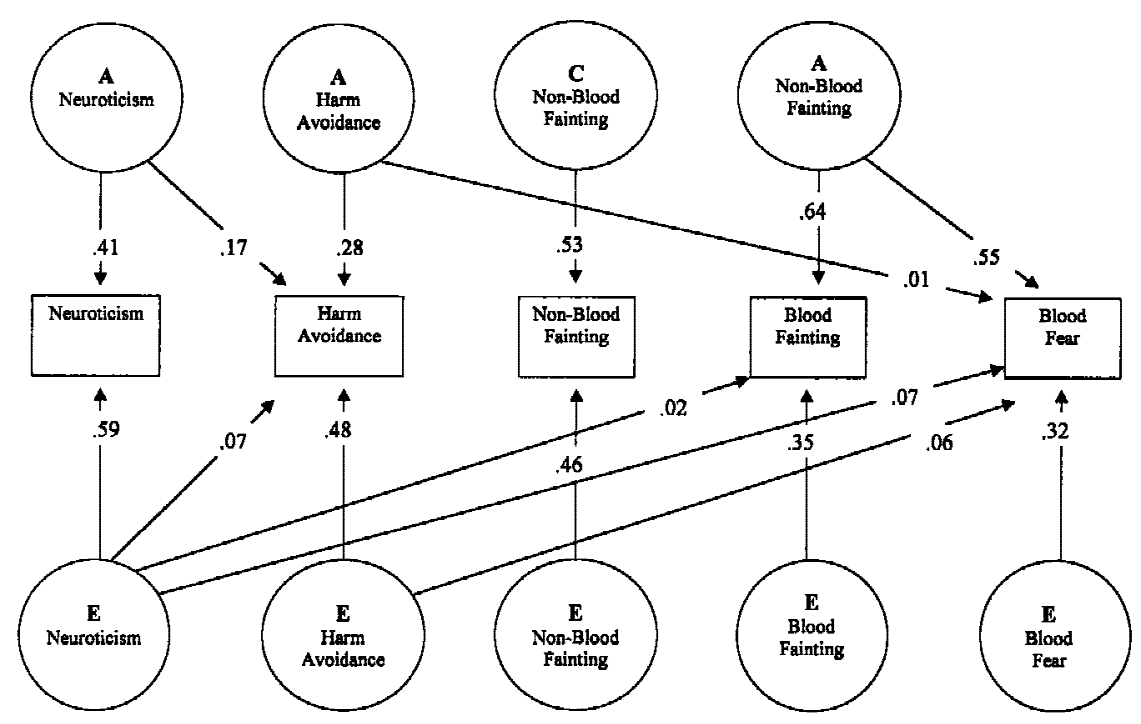

Fig. 1. Path diagram of displaying the significant variance components from an additive genetic (A), shared environmental (C), and nonshared environmental $(\mathrm{E})$ model of blood, injury, and injection fears.

the eliciting of fight or flight in the presence of the stimulus. It is reasonable to speculate that the anticipatory anxiety may be reflected in the construct of Harm Avoidance and the tendency to become anxious under threat may be reflected particularly by Neuroticism [Andrews et al., 1994]. If so, these data shed light on the triphasic reaction described by Page [1998], in which people with blood-injury-injection fears move through up to three phases. In the first phase they become tense in anticipation of exposure to a phobic stimulus. In the second phase they become anxious or fearful in the presence of the phobic stimulus and this may give way to the final phase involving fainting. Interpreting the present data in this context, in addition to the unique environmental experiences that give rise to blood fears, the tendency to become tense in anticipation (indicated by Harm Avoidance) would be caused by unique environmental experiences, the tendency to become overly fearful in the presence of a phobic stimulus (indicated by Neuroticism) would again be caused by unique environmental experiences, and the tendency to become faint (indicated by Non-Blood Fainting) would be caused by additive genetic factors.

However, there are a number of limitations in the present study, chief amongst which is the potential bias in the sample. The sample was recruited from among those who had elected to donate a blood sample. While the personal contact by a member of the research team undoubtedly reduced the ultimate attrition, it is reasonable that some people decline the invitation to participate due to fears associated with blood, injuries and injections. When this possibility was examined, no evidence of significant attrition was found for females. Therefore, the decision to limit analysis to the subjects for whom no evidence of attrition was found (i.e., females) minimised the impact of this bias but it is not clear to what extent the data remain biased.

In conclusion, the data indicate that like other specific phobias, fear of blood, injury, and injections are substantially caused by environmental factors that are unique to the individual. However, this phobia is unique in that some sufferers also faint in the present of their phobic object. The present data found that such fainting was caused by genetic factors that were shared with fainting in other contexts and that this same genetic factor gave rise to blood fears. Future research can continue to identify the unique environmental variables that cause blood fear, but it can also focus on the mechanisms whereby the genes associated with fainting can give rise to blood fears.

\section{ACKNOWLEDGMENTS}

This research was supported in part by grants from the National Health and Medical Research Council of Australia (Numbers 941177 and 971232) to Prof. Martin, the National Institute of Alcoholism and Alcohol Abuse to Dr. Andrew Heath of Washington University, St. Louis, USA, and the University of Western Australia's Department of Psychology to Dr. Page. We thank Professor David Copolov for access to the facilities at the Mental Health Research Institute of Victoria and we thank Pam Saunders, Louise O'Gorman, Theresa Pangan, and John Pearson. Most of all, we are grateful to the twins for their cooperation.

\section{REFERENCES}

Akaike H (1987): Factor analysis and AIC. Psychometrika 52:317-332.

Andrews G, Crino R, Hunt C, Lampe L, Page A (1994): "The Treatment of Anxiety Disorders: Clinician's Guide and Patient Manuals." New York: Cambridge.

Andrews G, Stewart G, Allen R, Henderson AS (1990a) The genetics of six neurotic disorders: A twin study. J Affective Dis 19:23-29.

Andrews G, Stewart G, Morris-yates A, Holt P, Henderson S (1990b): Evidence for a general neurotic syndrome. Br J Psychiatry 157:6-12.

Barlow DH (1988): "Anxiety and its Disorders: The Nature of Anxiety and Panic." New York: Guilford.

Carey G (1990): Genes, fears, phobias, and phobic disorders. J Couns Dev 68:628-632. 
Cannon WB (1927): The James-Lange theory of emotion: A critical examination and an alternative theory. Am J Psychol 39:106-124.

Cloninger CR, Przybeck TR, \& Svrakic DM (1991): The Tridimensional Personality Questionnaire: U. S. normative data. Psychol Reports 69: 1047-1057.

Engel GL (1978): Psychologic stress, vasodepressor (vasovagal) syncope, and sudden death. Ann Int Med 89:403-412

Eysenck HJ, Eysenck SBG (1975): "Manual of the Eysenck Personality Questionnaire." London: Hodder \& Stoughton.

Fyer AJ, Mannuzza S, Gallops MS, Martin LY Aaronson C, Gorman JM, Liebowitz MR, Klein DF (1990): Familial transmission of simple phobias and fears. Arch Gen Psychiatry 47:252-256.

Heath AC, Cloninger CR, Martin NG (1994): Testing a model for the genetic structure of personality: A comparison of the personality systems of Cloninger and Eysenck. J Pers Soc Psychol 56:762-775.

Henry JP (1976): Understanding early pathophysiology of essential hypotension. Geriatrics 31:59-72.

Jardine R, Martin NG, Henderson AS (1984): Genetic covariation between neuroticism and the symptoms of anxiety and depression. Genetic Epidemiology 1:89-107.

Jöreskog KG, Sörbom D (1993a): "PRELIS 2: User's Reference Guide." Chicago, IL: Scientific Software International.

Jöreskog KG, Sörbom D (1993b): "LISREL 8: User's Reference Guide." Chicago, IL: Scientific Software International.

Kendler KS, Neale MC, Kessler RC, Heath AC, Eaves LJ (1992): The genetic epidemiology of phobias in women: the inter relationship of agoraphobia, social phobia, situational phobia and simple phobia. Arch Gen Psychiatry 49:273-281.

Kleinknecht RA, Lenz J (1989): Blood/injury fear, fainting and avoidance of medically-related situations: A family correspondence study. Beh Res Ther, 27:537-547.

Marks IM (1987): "Fears Phobias and Rituals.” London: Oxford.
Marks IM (1988): Blood-injury phobia: A review. Am J Psychiat 145:12071213.

Neale MC, Cardon LR (1992): "Methodology for Genetic Studies of Twins and Families." Dordrecht: Kluwer Academic.

Neale MC, Walters EE, Eaves LJ, Kessler RC, Heath AC, Kendler KS (1994): Genetics of blood-injury fears and phobias: A population based twin study. Am J Med Genet (Neuropsychiatric Genetics) 54:326-334.

Öst L-G, Lindahl I-L, Sterner U, Jerremalm A (1984): Exposure in vivo vs applied relaxation in the treatment of blood phobia. Beh Res Therapy $22: 205-216$.

Öst L-G (1992). Blood and injection phobia: Background and cognitive, physiological, and behavioral variables. J Ab Psychol 101:68-74.

Page AC (1994): Blood-injury phobia. Clin Psychol Rev 14:443-461.

Page AC (1996): Blood-injury-injection fears in medical practice. Med J Aust 164:189.

Page AC (1998). Blood-injury-injection fears and fainting: Nature, assessment and management. Behav Change, in press.

Page AC, Bennett K, Carter O, Smith J, Woodmore K (1997). The BloodInjection Symptom Scale (BISS): Assessing a structure of phobic symptoms elicited by blood and injections. Behav Res Therapy 35:457-464.

Rachman SJ (1991): Neo-conditioning theory and the classical theory of fear acquisition. Clin Psychol Rev 11:155-174.

Robins LN, Helzer JE (1985): "Diagnostic Interview Schedule (DIS): Version III-A.” St. Luois, MI: Washington University School of Medicine.

Skre I, Onstad S, TorgersenS , Lygren S, \& Kringlen E (1993): A twin study of DSM-III-R anxiety disorders. Acta Psychaitr Scand 88:85-92.

Thyer BA, Himle J, Curtis GC (1985): Blood-injury-illness: A review. J Clin Psychol 41:451-459.

Vingerhoets AJJM (1984): Biochemical changes in two subjects succumbing to syncope. Psychosom Med 46:95-103. 